\title{
A Review of Pneumatic Actuators Used for the Design of Medical Simulators and Medical Tools
}

\author{
Thibault Sénac ${ }^{1}$, Arnaud Lelevé ${ }^{1, *(\mathbb{D})}$, Richard Moreau ${ }^{1}$, Cyril Novales ${ }^{2}$, Laurence Nouaille ${ }^{2}$, \\ Minh Tu Pham ${ }^{1}$ and Pierre Vieyres ${ }^{2}$ (D) \\ 1 Laboratoire Ampère (UMR 5005), INSA Lyon, Univ Lyon, F-69621 Lyon, France \\ 2 Laboratoire PRISME (EA 4229), INSA-CVL, Univ Orléans, F-18020 Bourges, France \\ * Correspondence: arnaud.Leleve@insa-lyon.fr
}

Received: 20 May 2019; Accepted: 24 June 2019; Published: 2 July 2019

\begin{abstract}
Simulators have been traditionally used for centuries during medical gestures training. Nowadays, mechatronic technologies have opened the way to more evolved solutions enabling objective assessment and dedicated pedagogic scenarios. Trainees can now practice in virtual environments representing various kind of patient and body parts including physio-pathologies issues. Gestures, to be mastered, vary according to each medical specialty (e.g., ultrasound probe orientations, or forceps installation during assisted delivery). Hence, medical students need kinesthetic feedback in order to significantly improve their learning capabilities. Gesture simulators require haptic devices with variable stiffness actuators. Existing solutions do not always fit the requirements because of their significant size. Contrary to electric actuators, pneumatic technology is low-cost, available off-the-shelf and offers a better mass-power ratio. However, it presents two main drawbacks: nonlinear dynamics and need for a compressed air supply. During the last decade, we have developed several haptic solutions based on pneumatic actuation (e.g., birth simulator, epidural needle insertion simulator) and, recently, in a joint venture with Prisme laboratory, a pneumatic probe master device for remote ultrasonography. This paper recalls literature scientific approaches on pneumatic actuation developed in the medical context and illustrated with the aforementioned applications to highlight the benefits.
\end{abstract}

Keywords: haptic training simulation; pneumatic control; medical robotics

\section{Introduction}

Simulators have been traditionally used for centuries during medical training as trainees have to improve their skills before practicing on a real patient. Classical simulators feature training boxes ("box trainers" in laparoscopy) [1], manikins, animals and corpses. They offer a convenient way to learn by trial and error. However, animals and corpses are not always available, are expensive and may raise ethical issues [2]. Training boxes require the physiological material to be prepared, which raises similar issues. Manikins, in turn, are available at a relatively low-cost [3]. They provide a realistic representation (in terms of shapes and tactile sensation). Trainees can use them to train on the human anatomy and learn how to palpate human body parts. However, physiologic materials are only imitated. Thus, the tactile and kinesthetic feel they render are not always accurate enough. Moreover, they do not provide ways to reproduce, each time, exactly the same characteristics of the experiments, and they generally do not record the trainees' gestures. Therefore, they cannot provide an objective assessment. As these simulators are composed of physical parts that are cut, pierced or sutured, regularly supplying them to cohorts of medical students is actually costly [3].

Although these former simulators have been used for years, nowadays mechatronic technology has opened the way to more evolved solutions enabling objective assessment and dedicated pedagogic 
scenarios. This evolution attempts to satisfy the need for efficient teaching tools invoked by public institutes such as the French HAS [4] (Haute Autorité de la Santé), which requests to "never do [it] the first time on a patient". Trainees can now practice in virtual environments on numerous body parts, including current and rare pathologies, for various kinds of patient (slim, elderly...). With these simulators, trainees can repeat a procedure several times without getting short of supplies (as it is the case of surgery on corpses), get prompt and objective feedback from the simulator, and determine which skills need to be improved [5]. Medical students need haptic feedback to significantly improve their learning curve, especially for gestures that require kinesthetic feeling [6] (kinesthesia is the ability to sense the movement and position of the body limbs). Thanks to kinesthesia, haptic training, and in particular kinesthetic focused training, extends vision based training. Some haptic simulators are now available on the market and are used in various medical sectors [7], such as endovascular surgery [8] or laparoscopy [9].

Gestures to acquire vary according to medical specialty: ultrasound probe orientations, needle insertion in rheumatology or anesthesia, and forceps installation during assisted delivery. These medical gestures require a haptic device based on a variable rendered stiffness device, commonly called Variable Stiffness Actuator-VSA) that has been suggested in the literature [10-12]. However, these systems are difficult to develop based on off-the-shelf devices. Solutions, based on electric or magneto-resistant fluids, do not always fit the training requirements because of their significant size or weight. Unlike electric actuators, pneumatic technology is low-cost, available off-the-shelf, easy to mechanically embed. Its mass-power ratio is also better and it provides a natural passive compliance by controlling the total amount of pressurized air filled inside chambers. However, it presents two main drawbacks: its nonlinear dynamics, which implies more complex control laws than the one used for electrical actuators, and the need of a compressed air supply. By modifying the pressure level in the actuator chambers, one can control in real-time the pneumatic stiffness (see Section 2.2), starting from $0.1 \mathrm{~N} / \mathrm{mm}$, according to Takaiwa et al. in [13]. For instance, Semini et al. introduced a VSA based on position-controlled hydraulic cylinders which has an even higher mass-power ratio and fewer issues from nonlinearity as oil is less compressible than air [14].

The main contribution of this paper is a review about compliant actuators and more particularly about the use of pneumatic actuation to provide compliant characteristics to actuators, in the frame of medical applications. We illustrate this review with three applications we designed. Two of them deal with haptic training simulation: a birth simulator (introduced in Section 3.1) and an epidural needle insertion simulator (see Section 3.2). The third one is about remote ultrasonography where a haptic pneumatic master is used in a teleoperation scheme (see Section 3.3).

Section 2 provides this review and Section 3 the aforementioned illustrations.

\section{Control of Compliant Pneumatic Actuators}

\subsection{Compliant Actuators}

Robotic applications have long raised the need for an actuation more evolved than just classical position control. This need comes from industrial use cases but also, more recently, from various fields of application such as rehabilitation robotics, haptics, robotic surgery, humanoids, and legged robots. Force control has been deeply studied in the literature. It consists of controlling the force applied by a tool in its environment. Its positioning is then directly dependent on the interaction force measured by force sensors or estimated from other signals, such as in [15]. In practice, the tool is controlled in force in one direction and in position in the other ones. It permits performing polishing [16] or friction stir welding [17] tasks, for instance. However, for interaction purposes and more advanced applications, it is required to control the stiffness of the actuator which should be stiff for precision positioning at a moment and then soft when the environment is not well known for instance [18]. Typically, a compliant behavior of the robot effector is required to enable soft grasping of fragile 
objects [19] and to prevent human injuries [20]. A balance between precision and regulated stiffness is necessary.

Haptic devices are robotic systems featuring this property. They are designed for interaction between a virtual tool in a computer-simulated situation [21], for teleoperating a remote robot handling an ultrasound probe [22] or multiple Unmanned Aerial Vehicles (UAV) [23]... For training purposes, the behavior of such devices must be realistic (as close as the real tool they simulate), and off-the-shelf haptic devices are not always suitable [24]. For practical reasons, commercial simulators usually embed electric actuators which provide force feedback mimicking - for instance, the behavior of a tool touching a human organ in a medical situation. Nowadays, the haptic control laws applied on electric actuators are well mastered. However, electric actuators have limitations for these kinds of applications. They have a low power-to-weight ratio, compared to pneumatic actuators. It is difficult to provide at the same time a high torque at high speed. They generally require the use of gears which limits their backdrivability. They also heat up when providing some torque at low speed. All of these limitations restrict their performance in rendering a fast and variable stiffness.

For a few decades, scientists have suggested complex mechanisms to provide this desired compliance to actuators, known as Variable Stiffness Actuators (VSA) or Variable Impedance Actuators (VIA). These actuators allow the equilibrium position and the stiffness to be tuned independently. Van Ham et al. present a state-of-the-art design of VSA in [25]. Most of these actuators are designed with two antagonist motors and passive compliant elements. An advantage of this design is that the control of the position and stiffness is obtained independently by controlling the positions of two electric motors. The main drawbacks of these solutions are their high cost as two electric actuators are needed to control only one Degree of Freedom (DOF), and their limited stiffness range due to the use of passive stiffness components [26].

Other approaches to obtain a compliant actuation are based on motor control strategies such as stiffness control [27], impedance control [28] or hybrid force-position control [29]. Most of these strategies have been developed for electromechanical actuated robots and require a force/torque sensor in order to measure the interaction force between the effector and the environment. It, therefore, implies knowing in advance where this interaction occurs. Moreover, these sensors are often expensive and fragile. In the absence of force/torque sensors, the actuators have to be backdrivable. It involves reducing gear ratios and, consequently, the torque or force range of the robot.

On the opposite side, pneumatic actuators have long been used in the industry only for basic translation needs (end-to-end motions in batch automation) as they provide a widely available low-cost solution with a high power-to-weight ratio compared to electric actuators. Obtaining linear motions requires mechanical motion transformation or the use of linear electric motors which are still expensive and bulky solutions compared to pneumatic cylinders. It is also a clean solution (compared to hydraulics) which requires easy maintenance, cannot explode and has a long working life. The term pneumatics is originated from the Greek word pneumos, which means to breathe [30]. The latter paper provides some links towards articles detailing the history of pneumatic control and also lists all the advantages of pneumatic solutions. The reason explaining why these actuators are not more used is their nonlinear characteristics which involve complex control laws when accurate positioning is required.

The use of pneumatic actuators for teleoperation has started in 1993 [31] and has been regularly studied since [32-34] (see Section 2.3 for medical applications). They are also used in soft robotics in order to perform a compliant grasp such as in $[35,36]$. They can be considered as VSA as their stiffness can be dynamically controlled by modifying the pressure in both chambers. Stimuli applied on the rod provoke instantaneous natural reactions without requiring a fast control loop. Note that some manufacturers propose non-magnetic actuators which make them Magnetic Resonance Imaging (MRI)-compatible and usable in medical applications such as needle placement, as in [37]. Recent works have introduced VSA featuring a novel kind of pneumatic actuators: Pneumatic Artificial Muscles (PAM) $[38,39]$. These actuators provide a greater amount of axial force than classical cylinders 
but with a meaner stroke and a greater nonlinearity. The use of two antagonist PAM forms a rotary joint with potentially higher torques than with traditional cylinders. The joint introduced in [39] is particularly compact but at the price of a restricted angular range. The more evolved VSA we could find consists of a magnetorheological clutch and pneumatic artificial muscles [40]. This association permits smoothly varying the stiffness and viscosity of the actuator.

Hereinafter, we present a typical pneumatic actuation chain with stiffness control to provide users with haptic feedback.

\subsection{Pneumatic Control Chain}

In the frame of this paper, we only consider pneumatic cylinders. They vary in shape (length, diameter), in rod configurations (output on one extremity or traversing), in pneumatic configurations (one or two active chambers, nominal supply pressure) and characteristics (stiction-less or non-magnetic, for instance). The number of parameters and their availability makes them affordable for a wide range of applications. In our applications, we use Airpe ${ }^{\circledR}$ (Airpot ${ }^{\circledR}$ Corp., Norwalk, CT, USA) models as they have low friction, which helps in getting accurate motions. The actuator model can be obtained using two physical laws: the pressure dynamics of the chambers and the fundamental mechanical relation. The pressure evaluation of the chambers with variable volumes is obtained with the following assumptions [41]:

- $\quad$ air is a perfect gas and its kinetic energy is negligible in the chamber,

- the pressure and the temperature are homogeneous in each chamber,

- the evolution of the gas in each chamber is polytropic and is characterized by coefficient $k$,

- the temperature variation in chambers is negligible with respect to the supply temperature,

- the temperature in each chamber can be considered equal to the supply temperature,

- the mass flow rate leakages are negligible,

- $\quad$ the supply and exhaust pressures are constant.

A fourth order state model of the pneumatic actuator in a horizontal position can be written:

$$
\left\{\begin{array}{l}
\frac{d y}{d t}=\dot{y} \\
\frac{d \dot{y}}{d t}=\frac{1}{M}\left(P_{p} S_{p}-P_{n} S_{n}-b \dot{y}-F_{p e x t}-F_{s t}\right) \\
\frac{d P_{p}}{d t}=\frac{k r T_{a}}{V_{p}(y)}\left(q_{m p}-\frac{P_{p}}{r T_{a}} S_{p} \dot{y}\right) \\
\frac{d P_{n}}{d t}=\frac{k r T_{a}}{V_{n}(y)}\left(q_{m n}+\frac{P_{n}}{r T_{a}} S_{n} \dot{y}\right)
\end{array}\right.
$$

where the model variables and parameters are listed in Table 1 . The pneumatic effort $F_{\text {pneu }}$ corresponds to the pressure difference in both chambers: $F_{p n e u}=P_{p} S_{p}-P_{n} S_{n}$. Two separate stiffnesses are defined: the pneumatic stiffness $K_{p n e u}$, and the closed-loop stiffness $K_{c l}$. The pneumatic stiffness $K_{\text {pneu }}=k\left(\frac{P_{p} S_{p}}{L_{p}(y)}+\frac{P_{n} S_{n}}{L_{n}(y)}\right)$ (where $L_{p}(y)=\left(\frac{l}{2}+y\right)$ and $L_{n}(y)=\left(\frac{l}{2}-y\right)$ ) corresponds to the passive stiffness of the actuator and varies according to the rod position and the pressure in the chambers. The closed-loop stiffness $K_{c l}=-\frac{\partial \Sigma F}{\partial y}$ (where $\Sigma F$ is the sum of every force applied on the cylinder rod) is the global one, perceived by the user when he/she handles the rod as it takes into account all the system dynamics. 
Table 1. Model parameters.

\begin{tabular}{|c|c|c|}
\hline Symbol & Description & Unit \\
\hline$y$ & Piston position & $\mathrm{m}$ \\
\hline$l$ & Stroke of the rod & $\mathrm{m}$ \\
\hline$\dot{y}$ & Piston velocity & $\mathrm{m} / \mathrm{s}$ \\
\hline$M$ & load mass & $\mathrm{kg}$ \\
\hline$S_{p}$ & Chamber $\mathrm{P}$ section area & $\mathrm{m}^{2}$ \\
\hline$S_{n}$ & Chamber $\mathrm{N}$ section area & $\mathrm{m}^{2}$ \\
\hline$P_{p}$ & Pressure inside chamber $\mathrm{P}$ & $\mathrm{Pa}$ \\
\hline$P_{n}$ & Pressure inside chamber N & $\mathrm{Pa}$ \\
\hline$b$ & Viscous friction coefficient & $\mathrm{N} \cdot \mathrm{s} / \mathrm{m}$ \\
\hline$F_{s t}$ & Stiction force & $\mathrm{N}$ \\
\hline$F_{\text {pext }}$ & Force applied by the atmospheric pressure on the cylinder piston ${ }^{1}$ & $\mathrm{~N}$ \\
\hline$r$ & Perfect gas constant & $\mathrm{J} /(\mathrm{kg} \cdot \mathrm{K})$ \\
\hline$T_{a}$ & Temperature of the supply air & K \\
\hline$V_{p}(y)$ & Chamber $\mathrm{P}$ volume at position $y$ & $\mathrm{~m}^{3}$ \\
\hline$V_{n}(y)$ & Chamber $\mathrm{N}$ volume at position $y$ & $\mathrm{~m}^{3}$ \\
\hline$q_{m p}$ & Mass flow rate entering the chamber $\mathrm{P}$ & $\mathrm{kg} / \mathrm{s}$ \\
\hline$q_{m n}$ & Mass flow rate entering the chamber $\mathrm{N}$ & $\mathrm{kg} / \mathrm{s}$ \\
\hline$u_{p}$ & Chamber-P-servovalve input voltage & $\mathrm{V}$ \\
\hline$u_{n}$ & Chamber-N-servovalve input voltage & $\mathrm{V}$ \\
\hline
\end{tabular}

It has to be noticed that this model is available also for a single rod cylinder. In the case of a double rod cylinder, $S_{p}=S_{n}=S$ so $F_{\text {pext }}=0$.

When ultra-low friction pneumatic cylinders are used, the stiction force $F_{s t}$ can be considered as negligible. The authors in [30] provide more information about friction models. Such actuators are supplied either by on/off solenoid valves or by servo-valves. Solenoid valves act as open/close gates for the air entering in each chamber of the pneumatic actuator. It opens the way to air when a voltage is supplied on their input. Advanced solenoid valves manage the input/output of air simultaneously into both chambers, enabling one chamber to be supplied with pressured air while the other one is connected to exhaust. However, this kind of pneumatic actuator driver is generally limited to the applications where low positioning precision is sufficient as the actuation is performed in an open loop. Nevertheless, in [42], this approach has also been used for teleoperation purpose, with sliding mode control. It has the advantage of requiring widespread low-cost components, but it generates much commutation noise.

For accurate positioning, servo-valves are preferred. They permit continuously controlling the air flows. Their main disadvantage is their higher cost compared to widespread low-cost solenoid valves. A second disadvantage is their behavior: the air mass flow rates can be considered as a nonlinear function of the input voltage and the corresponding chamber pressure. Accurate control requires its modeling. Two methods exist in this purpose. Both are based on an experimental characterization. The first one consists of identifying a (most of the time polynomial) function parameters fitting the behavior of the servo-valve [43]. The second one consists of using the experimental characterization results to produce an input/output map of the servo-valve. These two models can then be used 
to simulate the behavior of the servo-valve or be embedded in a model-based controller. They are determined with static values in steady state mode. The dynamics are neglected as the servo-valves are much faster than the actuator dynamics. Figure 1 depicts such a map for a Festo ${ }^{\circledR}$ MPYE-5-M5-010-B. It provides the relation between the mass flow rate entering the connected chamber, the control voltage, and the chamber pressure. Several configurations are available, such as a single $5 / 2$, two $3 / 3$ or four 2/2 servo-valves in order to get increasing control on air input and output flows [30]. However, in [44], we determined that we could obtain satisfying results for stiffness control with only one 5/2 servo-valve and a backstepping based controller.

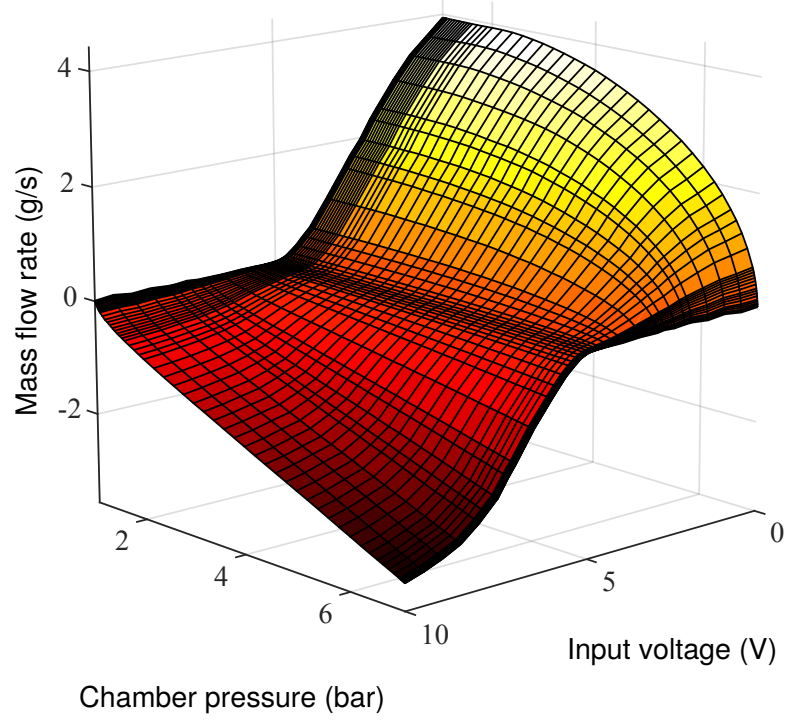

Figure 1. Servo-valve relation between input voltage, actuator chamber pressure and mass flow rate of the air entering the chamber.

The control can be performed with many computing solutions which are not specific to pneumatic systems. One has to take into account that, for haptic applications, a sampling rate higher or equal to $1 \mathrm{kHz}$ is required to get a sufficient bandwidth. For prototyping purpose, we usually embed our control laws in a dSPACE ${ }^{\circledR} 1104$ control board which acquires in real-time sensor signals and generates the servo-valve control signals. The code is generated from Simulink ${ }^{\circledR}$ models.

To close the control loop of servo-pneumatic systems, position sensors and pressure sensors are used. As it is very complex to integrate the pressure sensors inside each chamber, we generally put them as close as possible of the cylinder air connectors. Position sensors are not specific to this kind of application. Linear potentiometers or Linear Variable Differential Transformers (LVDT) usually fit.

When necessary, non-specific force sensors can be embedded. The article [30] lists common sensors used in pneumatic actuation applications. A schematic of the whole architecture with two servovalves is shown in Figure 2.

The development of fast servo-valves, coupled with modern robust nonlinear control laws based on sliding mode [45] and backstepping [46], allowed the development of accurate position or force controllers. Toedtheide et al. provided a state-of-the-art compliant control for pneumatic cylinders in [47]. In [47], most of the solutions make use of a sliding mode controller and require two proportional servo-valves for a single cylinder. More details are provided in Section 2.4. 


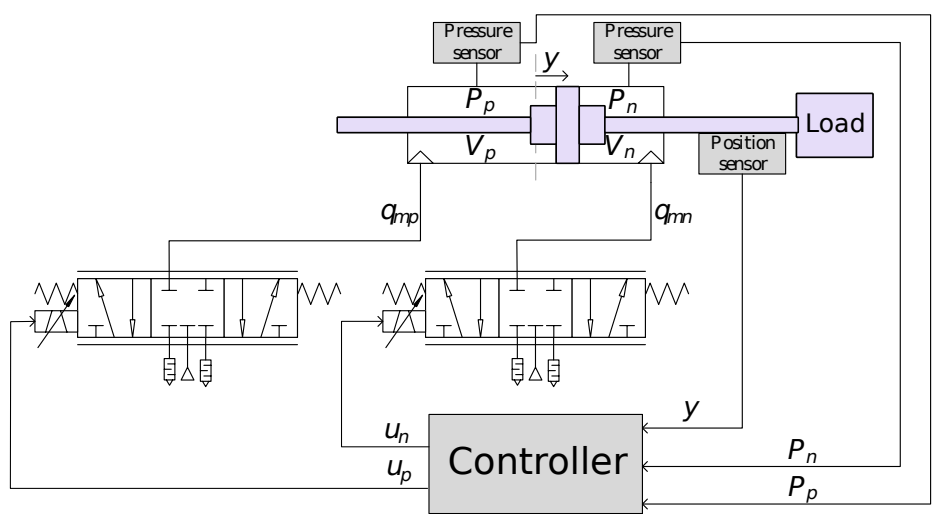

Figure 2. Electropneumatic system.

\subsection{Use in Medical Systems}

The variety of medical applications of pneumatic actuators is progressively increasing. A recent review [48] lists the pneumatic actuated medical simulators. The authors focused on haptic simulators used for palpation and Minimal Invasive Surgery (MIS) training.

We can also cite [49] where pneumatic properties are used to simulate the behavior of a catheter in the frame of gastrointestinal endoscopy. Their use for teleoperation medical purpose has been constant. A sample is provided in [50] for remote needle insertion in an MRI. They are also used in some surgical tools such as in [51] where a cylinder actuates a forceps with wrist joint for MIS surgery.

Pneumatic actuators are also used for human rehabilitation [52] and in prosthetic devices [53]. Orthotics are orthopedic apparatuses used to improve the functionality of movable parts of the body. Exoskeletons are orthotics that are external to the human body [54]. Exoskeletons can be used for various applications where humans require gesture assistance. Out of them, we can cite their use for rehabilitation (such as in [55] for the upper limb and [56] with a teleoperated exoskeleton). In 2016, Gopura et al. reviewed active upper-limb exoskeleton robots [54]. Veale et al. listed lower-limb and full orthosis types [57]. These reviews show that pneumatic actuation has been used in orthotics [54,57]. According to [54], about $20 \%$ of the upper-limb studied orthotics were actuated pneumatically, either with cylinders or muscles.

The combination of pneumatics and soft materials have opened the way to new applications of rehabilitation, aiding the elderly, preventing potential injury, or providing assistance to healthy individuals. Compared to the aforementioned orthotics which are rigid solutions, soft robots are less expensive, more functional, and improve the safety in the interaction. Indeed, soft materials can naturally comply with the human tissue to which they are interfacing, so that damage to the patient disappears. They can be used inside or outside the body. When located outside the body and at a human scale, soft robots are also termed "wearable robotics" [58]. They are particularly suited for rehabilitation since prevention of damage to the wearer is of utmost importance. Cianchetti et al. have recently written a review of medical applications of soft robotics [59]. They also report the use of pneumatic actuation.

A review about fluid-driven soft robotic solutions has been proposed in 2017 by Polygerinos et al. [58]. Besides aforementioned orthotics, it illustrates the applications of such robots as implantable devices such as cardiac pumps or intra-aortic balloon pumps, or as replacement of rigid Minimally Invasive Surgery (MIS) tools. In these applications, electro-thermal-pneumatical actuators can be used to provide fluids to fluidic actuators installed into the human body [59]. As a sample, we introduced in 2009 a biologically-inspired continuum robot applied to medical surgery-colonoscopy [60]. This system was designed with a pneumatic-driven flexible robotic manipulator which is able to center itself in a tubular, compliant and slippery environment by adjusting its shape in real time to avoid the contact with the tube wall. 
Pneumatics can also be used for tactile interfaces, such as in [61] for the simultaneous control of shape and mechanical properties in a tactile display. Some applications are listed in [48]. Other samples are introduced in [62] where pneumatic actuation is used to provide tactile feedback to achieve intraoperative localization of an early-stage gastric tumor that cannot be visually detected during laparoscopic surgery, or in [63] where a pneumatic actuated haptic glove featuring silicone-made cavities located at the fingertips and the center of the palm of the user make users perceive soft skins with different shape, stiffness, and homogeneity. On the other end of the teleoperation chain, it can be used also for force sensing like in [64] where a force measurement is performed thanks to the air pressure variation inside a pneumatic balloon in contact with an object.

As pneumatic actuation has its own drawbacks, some applications mix pneumatics with other kinds of actuation. For instance, in [65], pneumatic actuation is mixed with piezoelectric one to teleoperate a robot for MRI-guided needle insertion. In the remote echography application detailed in Section 3.3, the master is actuated with a pneumatic cylinder while the slave robot is only electric. In [66], a linear hybrid actuator featuring a pneumatic cylinder and a magnetorheological brake make use of the advantages of both actuations: the magnetorheological brake raises the amount of applied force in opposite motion and compensates for the side effects of the pneumatic cylinder. The brake provides a continuous action by means of a Proportional-Integral-Derivative (PID) controller, while the cylinder is supplied with two solenoid valves. Authors show that this hybrid actuator enhances the performance in position tracking and force disturbance rejection compared to a purely pneumatic control algorithm. The mix can also be performed with passive materials such as in [67] where a forceps manipulator mechanism features two pneumatic cylinders and an elastic bending mechanism.

\subsection{Control}

Position or force control of pneumatic cylinders is well mastered nowadays in the fluid power community, as detailed in $[7,68]$. The first models and control laws for pneumatic systems have been introduced by Shearer in 1956 [69]. It is possible to control such actuator with a classical PID controller. However, it provides low performance because of the nonlinearities of the servo-valve, the compressibility of the air, the saturation of the air pressure inside the chambers (limited to the supply level) and mechanical issues such as hysteresis, Coulomb friction, dead zones or backlash. Several solutions are suggested to enhance the performance obtainable with linear controllers: fractional order, cascade feedback, fuzzy PID,... They are listed in [30].

When nonlinear control strategies appeared, they have been progressively applied to pneumatic systems to raise their performance. For instance, adaptive control applied on pneumatic systems was first introduced in 1988 by Wikander [70]. To bypass the nonlinear behavior of the pneumatic actuation chain, a feedback linearization approach has been suggested by Chickh et al. in [71], which transforms the system into a Single-Input-Single-Output (SISO) system. It is then used with a Generalized Predictive Controller (GPC), which is one of the control techniques that belong to the Model Predictive Control (MPC) family. Predictive control is particularly suitable for applications where future desired positions are known a priori. Another approach from the same authors consists of realizing an output feedback pressure control via Linear-Matrix-Inequality (LMI) optimization [72].

The aim of this choice is to tune the system performance in terms of time response, steady state errors and disturbance rejection. The $\mathrm{H}_{\infty}$ loop compensates the nonlinearities and brings some robustness to the force control with respect to model uncertainties. A GPC control is then performed on top of this inner loop. Another potential interest of LMI is to help define a multiobjective optimization including removing the chattering effect of the control signal for high dynamic closed-loop poles.

Current widespread approaches are based on a backstepping method (as in [73] with an adaptive variant) and sliding mode control with some variants (reduced order, two variable, integral,...) [74]. Some solutions are also based on Fuzzy Logic (FL), neural network-based models and Neuro-Fuzzy control [30]. Latest research in position control of pneumatic actuators promote, for instance, the use of high gain approach combined with backstepping control [75]. It is difficult to compare the performance 
of all these approaches as they have not been tested on the same bench. They may also each have some advantages in different applications.

While the research on position tracking is rich in recent enhancements, stiffness pneumatic control solutions evolve more slowly. Nonetheless, we showed in [44] that, instead of controlling each mass flow rate entering each chamber, it is easier to define two virtual flow rates: the active mass flow rate, denoted $q_{m A}$, and the pressurization mass flow rate $q_{m T}$, using the reversible "A-T transform" introduced in [76]. In [44], we introduced two control laws for pneumatic actuation with stiffness control. Controlling this stiffness allows simulating different human organ behaviors such as rigid ones (bones) and soft ones (kidney...). The impedance control law that is often used for electrical actuators was adapted for pneumatic actuators. It consists of two nested loops. The inner loop is a force control loop and the outer one was an impedance control loop that allows the closed-loop stiffness and damping to be tuned. The latter loop could be considered as a state feedback loop. We also introduced a second control law based on a nonlinear method: backstepping position control synthesis with a gain tuning strategy to control the stiffness [77]. It simultaneously controls both the actuator position and the pneumatic stiffness (it can also be used to control the actuator closed-loop stiffness [76]). The performance of this control law has been experimentally compared in [44] with the impedance control law introduced in [78] with gravity compensation. The backstepping position controller with the closed loop stiffness tuning strategy is more accurate for the position tracking than the linear impedance controller, in particular on the vertical axis. However, this controller is also more sensitive to stick and slip phenomenon. The closed loop stiffness tuning has the same performance with both controllers. Since, we reused this backstepping-based controller in an epidural anesthesia training simulator (see Section 3.2), in order to render the behavior of the syringe connected to the needle [79].

In this section, we exposed the main principles of compliant actuators required for various aforementioned medical applications. We illustrated a classical pneumatic actuation chain and enumerated the main control law approaches in the literature. We exposed the pros and cons of pneumatic actuation for this purpose. To sum up, this type of actuation is increasingly exploited when electric one does not fit with haptic performance requirements. Mixed actuation samples have been found in the literature and used in the applications detailed in Section 3.2.

\section{Applications}

This section illustrates how compliant pneumatic actuators are applied into medical tools and simulators.

\subsection{Birthsim: A Simulator to Train on Difficult Childbirths}

Since 2004, in order to train students in obstetrics and midwifery, particularly for difficult childbirths, scientists have been proposing simulators more evolved than traditional passive manikins. For instance, Lapeer et al. chose to develop an augmented environment to simulate obstetric forceps delivery [80]. Their simulator enables users to visualize their instruments inside the maternal pelvis. There is, however, no haptic device to train on forceps extraction. Sielhorst et al. [81] and Abate et al. [82] have worked on delivery simulators coupling augmented reality with an haptic device. The first one is based on a 6 DOF industrial robot to control the head trajectory. This kind of robot is easy to use, but the range of the available forces is oversized for this kind of application. The second one uses an industrial exoskeleton haptic device, coupled with virtual reality goggles, which allows a perfect immersion of users and a good haptic feedback. However, as the user is the only one person immersed in the simulation, it is not appropriate for a teamwork practice. Some simulators are commercially available and one of the most advanced is the NOELLE simulator [83]. It is dedicated to team training, but it is not adapted to evaluate a practitioner specific gestures.

During the past few years, Ampère laboratory has developed a childbirth simulator (called BirthSim) [84] which compensates for the limitations of existing ones. It has been designed 
especially to train and evaluate the instrumental delivery gestures. It consists of anthropomorphic models of a maternal pelvis and fetal head. Obstetrics forceps are instrumented to measure their displacements [85]. Several scenarios have been implemented on the BirthSim simulator. Trainees can thus proceed to a risk free training on forceps blade placement and forceps extraction. A visualization interface is also available to allow the trainee to see inside the pelvis and improve his gestures while using forceps.

The BirthSim simulator now has two pneumatic actuated DOFs (cylinders 1 and 2 in Figure 3a) to render the translation of the head of the fetus in the vertical symmetry plane and the efforts involved during deliveries. The rotation of the fetal head around the longitudinal axis of cylinder 2 is electrically controlled. A 2 DOF backstepping position control has been implemented, with gain tuning, in order to control the closed-loop stiffness and damping, as introduced earlier. Details and experimental results are available in [44].

The experimental results showed that the Backstepping position and stiffness controller are more accurate for the position tracking in particular on the vertical axis However, this controller is more sensitive to stick and slip phenomenon. This performance can be improved by adding a linear guide to the horizontal cylinder to avoid the bending of the cylinder rod. Another way to improve the accuracy of the position tracking is adding a LuGre model which is suitable to model the stick and slip phenomenon. An other improvement can be performed by adding a robust observer for the external disturbance force.

In order to validate the four-degree-of-freedom architecture, two experiments simulating normal childbirths have been performed. Even if the simulation model was incomplete (some soft tissues were not simulated so that some rotations and the foetal motion were not accurate), two expert obstetricians could validate the enhancement in realism since the previous version with only one degree-of-freedom.

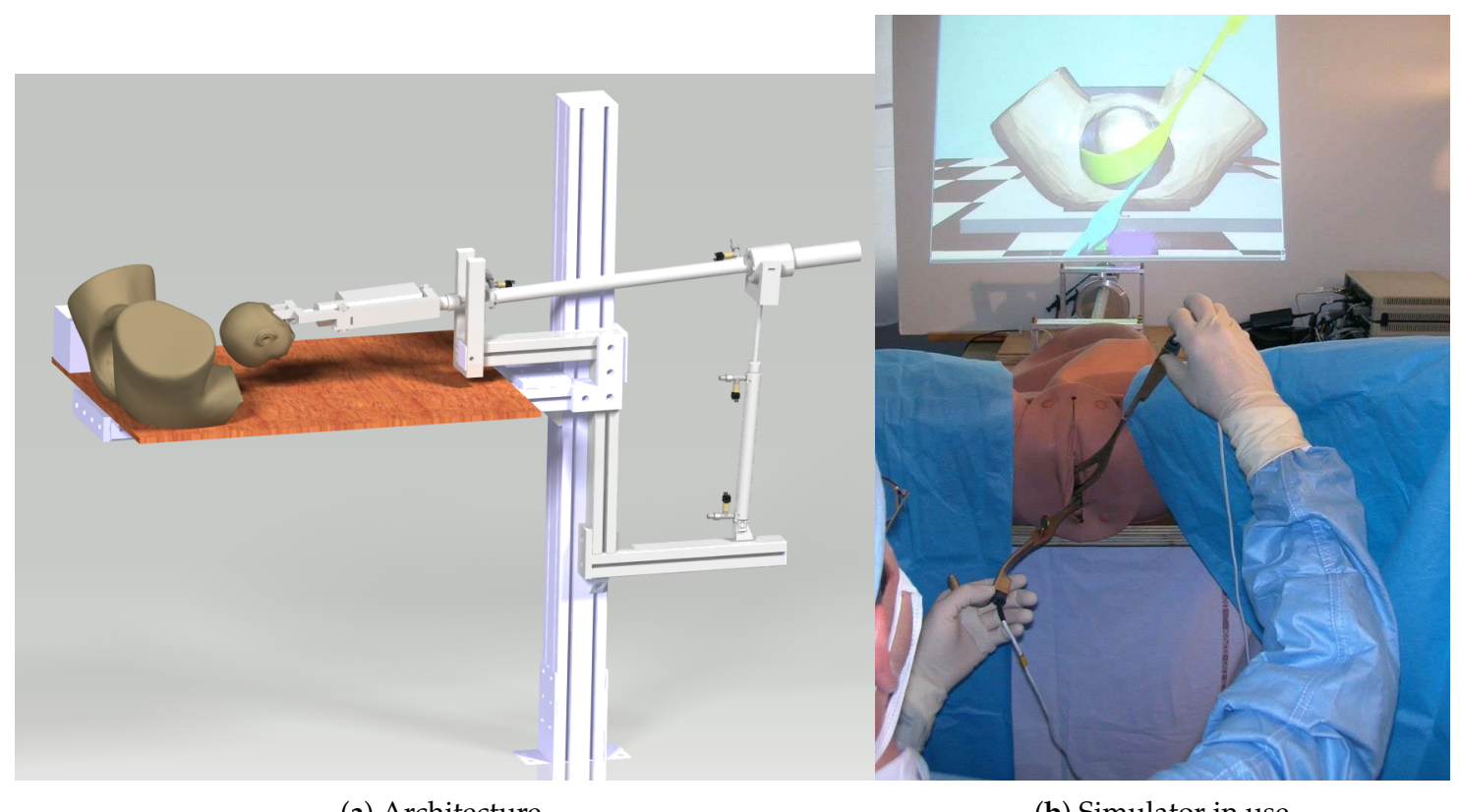

(a) Architecture

(b) Simulator in use

Figure 3. BirthSim: difficult chilbirth haptic simulator.

\subsection{Perisim: Epidural Needle Insertion Simulator}

Epidural anaesthesia, despite being a commonly used medical gesture performed mainly during childbirth delivery, remains a very complex and hard to learn gesture [86]. This is mainly due to the fact that the procedure is mostly performed blindly, relying solely on haptic cues and their interpretation by the anaesthetist. To perform such a gesture, the practitioner has to insert a Tuohy needle between two vertebrae while injecting a fluid using an epidural syringe. To perform the anaesthesia, the Tuohy 
needle has to go through several physical layers to finally reach the epidural space. Throughout the insertion, the anaesthetist experiences an increasing resistance coming both from the needle insertion and from fluid injection. This resistance reaches its maximum in the ligamentum flavum to then plummet, creating what is commonly called the loss of resistance (LOR) principle. It is this principle that allows physicists to know they reached the epidural space. Due to the relatively high forces exerted simultaneously on the needle and on the plunger of the syringe, the procedure is really demanding in terms of precision as the epidural space is usually only about $4 \mathrm{~mm}$ wide. In consequence, this particular medical gesture has quite a steep learning curve and may require up to 90 attempts to be performed with only $80 \%$ efficiency [87], which cannot be enough for healthcare applications.

Some training support solutions have been developed in the form of manikins or complete robotic applications. Most of the suggested solutions have been listed and compared in [87], which considers 17 manikin based solutions and 14 computer based ones. According to this study, no any ideal solution existed. Out of computer based solutions, we can highlight, for instance, the works of Manoharan et al. [88], Magill et al. [89], Dubey et al. [90] or Thao et al. [91], who introduced haptic simulators for this particular procedure. These simulators, however, provide an incomplete representation of epidural anaesthesia. Concerning needle insertion, these solutions often developed a custom haptic device to generate the necessary haptic cues, but the only included simplified representation of the procedure limited, for example, in terms of degrees of freedom or ignoring potential bone contacts. Regarding the loss of resistance, the simulations are very simplified (if present), only using on/off solenoid valves.

Vaughan et al. [87] have drawn some outlines as to what would be the perfect epidural needle insertion simulator. It has to be customisable (to represent various patient types) and should provide a haptic device for the syringe manipulation (with the LOR feel), paired with a 3D interface for the needle insertion. However, most of the current simulation options are only able to reproduce what is called 100\% (binary) loss of resistance behavior, which is encountered only in the "average" and "easy" cases. The difficult cases require a continuous feedback with a specific force feedback pattern.

Therefore, we designed a haptic simulator able to reproduce the rendering of the loss of resistance experience with a generic haptic device paired with a pneumatic cylinder. In this simulator, the electric haptic device (a Virtuose ${ }^{\mathrm{TM}} 6 \mathrm{D}$ from Haption,) exists to reproduce the haptic cues generated by the needle insertion only. The pneumatic cylinder (an Airpel Anti Stiction ${ }^{\circledR}$, double acting pneumatic cylinder), mounted on the effector of the Virtuose, is employed to emulate the syringe used in the real application and its purpose is to emulate the loss of resistance. All of this is visible in Figure 4 (the Virtuose is partly hidden under the green cover, and the syringe simulation part is depicted in the right picture).

To tune accurately enough the prototype, we asked trained anaesthetists to try and assess it. It allowed us to apply some necessary adjustments to some simulation parameters, such as the values of the the resistant force created by the pneumatic cylinder. Once the parameters were set to obtain realistic simulations, we recorded complete procedures. The aim of the first experimental study was to know whether it would be possible to differentiate an experienced user from a novice through the use of this simulator. 


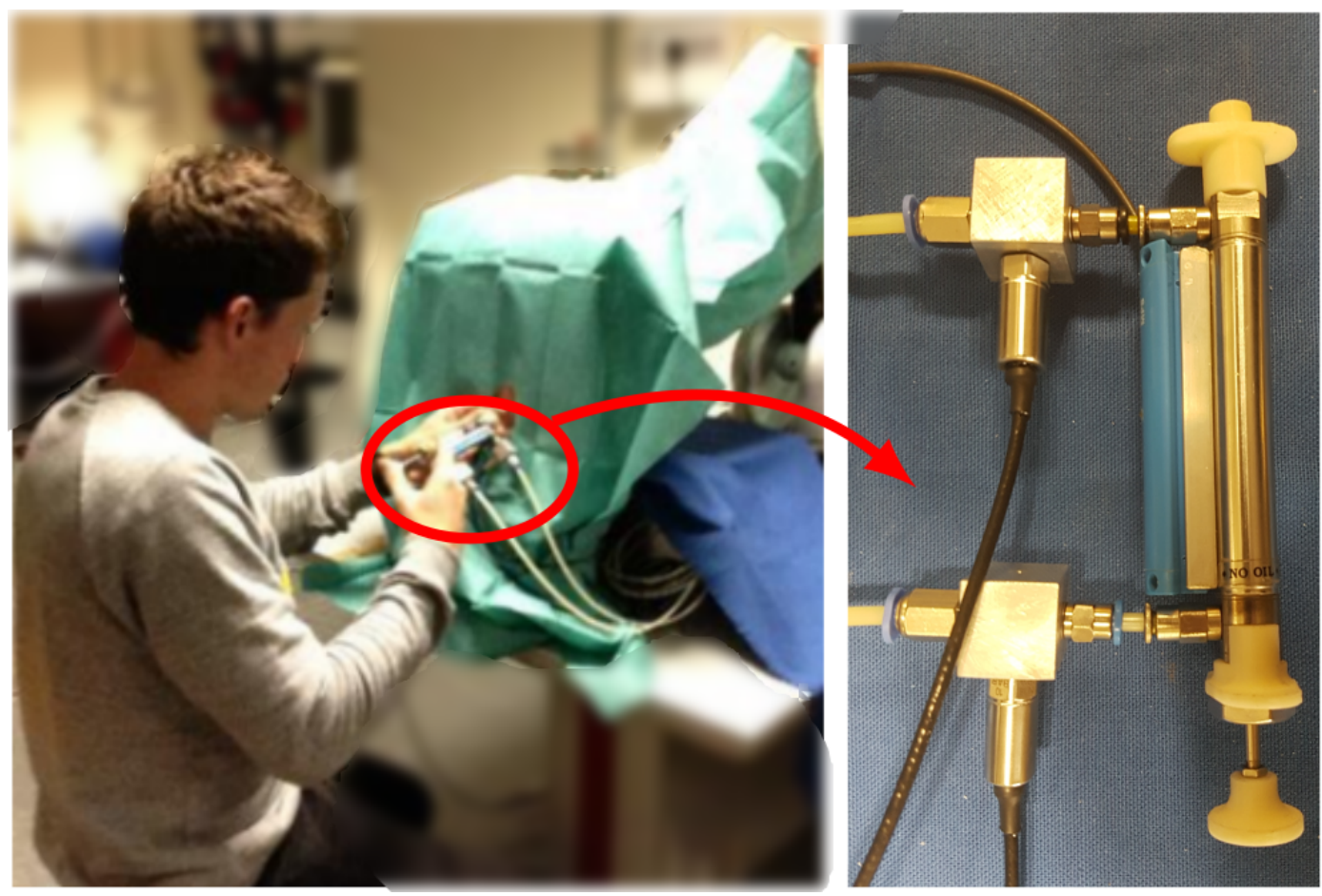

Figure 4. Complete prototype setup (left) and pneumatic cylinder setup (right).

We set up three kinds of patients for the first test sessions. The first patient type was the average patient, which represents an "easy" case and serves as a basis from which we derived the others. The parameters changed for the other patient types were: the length of the derma layer, the length of the epidural space layer, and the LOR speed (i.e., the speed of transition between the highest resistant force in the ligamentum flavum to the lowest in the epidural space). The patient characteristics are available in [92].

The tests were performed with two experts and six novices. Up to 24 variables were simultaneously recorded. Detailed results are available in [92]. On initial examination, we analyzed the success rate per patient type, the velocity of the needle tip along the insertion path. Finally, we introduced an indicator computed by dividing the proportion of emptied syringe by the distance $d$ traveled by the haptic device from the puncture of the derma to the end of the procedure along the elastic plane normal vector. Only the unskilled users failed at some attempts. The overall results show that novices obtain a success rate of $60 \%$ (versus $100 \%$ for the experts). Their success rate is better for the calcified/average cases and worse for the overweight ones. This indicates that the LOR phenomenon reproduction played an important role in how the unskilled users detected the epidural space. This confirmed the need for a customizable LOR rendering instead of a binary LOR behavior. In addition, regarding the aforementioned indicator, the experts tend to have a much higher score than the novices, showing that they usually use a greater portion of the cylinder length ( $d$ being constant regardless of the patient type). This might be a way for the skilled users to retrieve as much haptic information as possible. This may help them to identify their current position with much more precision than only detecting the LOR. Furthermore, concerning the novices, the standard deviation of the indicator is also quite high showing a wide variety of use.

As a conclusion, the overall results of this first study are quite encouraging and indicate that such a simulator might be realistic enough to provide an efficient training tool in the future. However, some points might need more work such as introducing a very distinct feel of cutting through the ligamentum flavum, which, according to our experts, feels like friction and cracklings. Moreover, according to their feedback, when the needle is in the ligamentum flavum, the syringe plunger should give the impression that it is locked. Finally, we are preparing an automatic classification of the users method in order to provide rapid, objective and automatic user assessment. This requires more trials with more users in 
order to generate a representative training data set. We will also assess the relevancy of such a tool in a teaching environment.

\subsection{Remote Ultrasonography Haptic Master}

Currently, over a quarter of emergency admissions requires an ultrasound examination. This low-cost examination technique is radiation free and frequently used to help medical ultrasound experts deliver a preliminary diagnosis. Depending on state health policies, the ultrasound imaging-based diagnosis is performed either by trained physicians or by specialized ultra-sonographers. In both cases, the specialist must be in close proximity to the patient in order to maintain and move the ultrasound probe on the selected anatomic area to undertake the examination. The sonographer assimilates the position of the probe with his/her hand motion to analyze the subsequent $2 \mathrm{D}$ ultrasound images. To compensate the lack of ultrasound expert in medically isolated settings and in order to deliver equitable healthcare, since the late 1990s, several concepts of remote robotized ultrasonography, using light-weight body mounted robots, have been developed, enabling the sonographer to move an ultrasound probe remotely on a patient. Syrtech [93], Teresa [94], TER [95] or Masuda [96] used robots attached to a table next to the patient or posed on the patient's body maintained by an assistant. Previous trends were light-weight body-mounted robots positioned on the patient's body Najafi's parallel robot [97], Prosit 1 serial robot [98] or FASTele remotely controlled with a smartphone [99] (Figure 5).

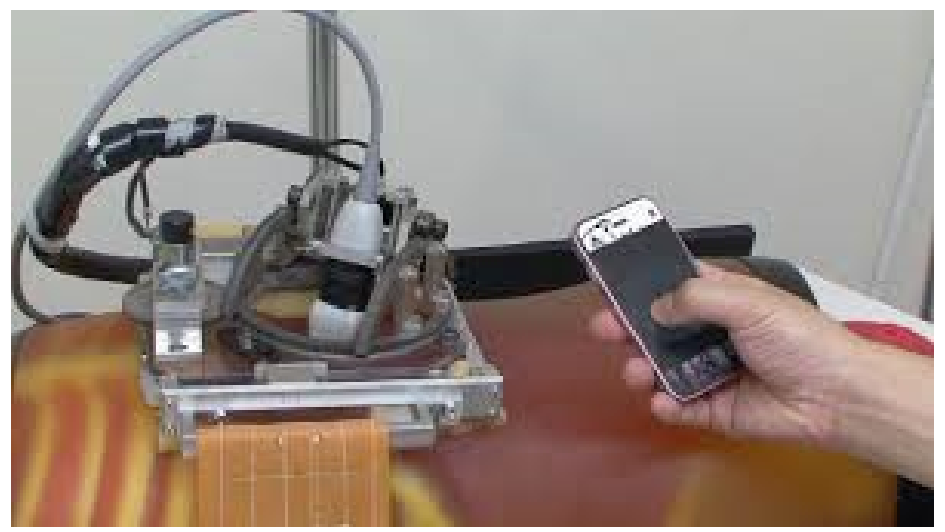

Figure 5. FASTele robot [99].

A paramedic maintains the robot on the patient anatomical zone defined by the distant medical expert using a videoconferencing system, while the distant sonographer controls the probe orientations using a dedicated input device (Figure 6). Current trends are compliant "industrial" robots used for medical purposes [100]; their costs are cheaper than dedicated bodymounted robots, and these robots offer a larger workspace with great safety [101]. Moreover, they allow for controlling them in torque, to dynamically adjust the stiffness for the contact between the robot and the human body like with the LBR Med robot from Kuka Medical Robotics (See https:/ / www.kuka.com/en-gb/industries/healthcare/kuka-medical-robotics).

ReMeDi project has designed a robotic mobile base with an Accrea arm (7 DOF) to increase the workspace and allows reconfiguration [102]. 


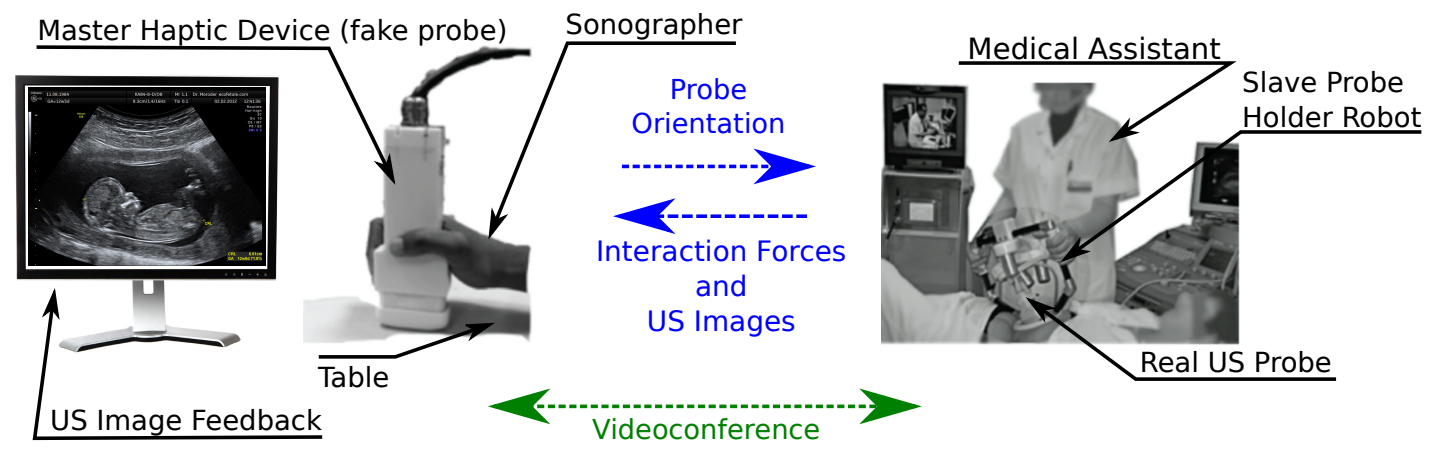

Figure 6. Remote echography.

The ergonomics of the device remain a key requirement for the sonographers not to be disrupted by the distance involved in the telemedicine act, and to only focus on his/her medical gesture and procedure. As such, when a master ultrasound probe haptic device is used, it has to provide the sonographers with a full transparency, i.e., high force and position rendering, to perform a robotized remote ultrasound scan as if they were in close proximity to the patient. The master device must be adapted to the sonographer's hand and to his/her expertise. Off-the-shelf 3D haptic interfaces might be used, but their kinematic chain completely differs from the one offered by the standalone ultrasound probes that sonographers are used to. The practitioner thus has to readjust his/her hand motions to the proposed input devices, which therefore interferes with the medical act. Courreges [103] suggests providing the sonographer with a master ultrasound probe without a mechanical link to the environment, similar to a standard ultrasound probe. The tele-ultrasound device was developed and patented by Prisme laboratory (Figure 7) and industrialized by AdEchoTech.

This telemedicine robotized ultrasound system is divided into several parts:

- $\quad$ on the patient side, a slave robot holding the ultrasound probe;

- $\quad$ on the medical expert side, a hand-free probe replica;

- $\quad$ a TCP/IP connection links the two parts.
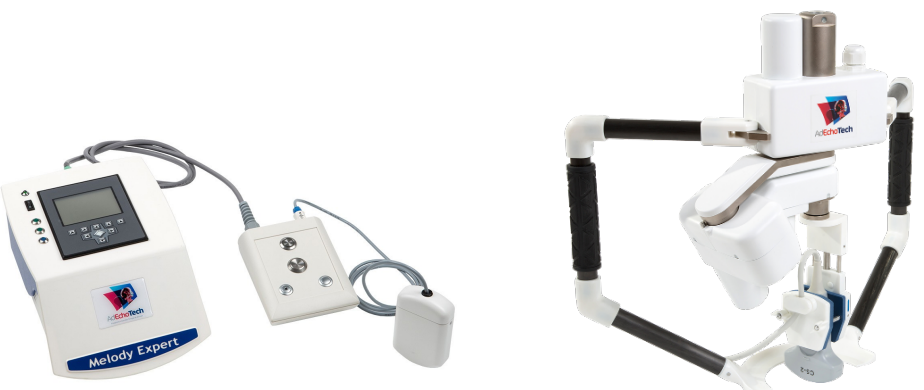

Figure 7. Adechotech Melody system.

Thanks to the haptic master probe concept, doctors in training or specialized sonographers should improve their learning curve to control the distant robot [104], as when performing a standard ultrasound examination, sonographers need to feel the interaction between the real ultrasound probe and the patient's body. Indeed, similarly to when performing their medical act, where they need to feel whether they touch hard or soft body parts, medical experts need to have a rendering of the patient's body and real probe interaction stiffness changes. This is even more true at a distance as the practitioner only has a view of the patient via a videoconferencing camera system. The master probe, held by the ultrasound expert, should thus be actuated to render the interaction forces, and therefore stiffness, between the real remote ultrasound probe and the patient's body. Even if it concerns only one dimension, this force-feedback is a real ergonomic and technological challenge; it is important 
to preserve weight and dimensions comparable to what of a standard ultrasound probe. Experiment results with sonographers gave the following requirements, which correspond to classical dimensions of ultrasonography probes and measures performed on our first prototype:

- a reversible mechanism with small dimensions ( $12 \mathrm{~cm}$ long, $6.5 \mathrm{~cm}$ wide and $3.5 \mathrm{~cm}$ thick at most),

- a continuous force feedback level of about $15 \mathrm{~N}$ and a maximum force of about $25 \mathrm{~N}$, in the $z$-direction normal to the patient's skin,

- a maximum stroke distance of $50 \mathrm{~mm}$ with a maximum velocity of $200 \mathrm{~mm} / \mathrm{s}$,

- $\quad$ an Inertial Measurement Unit (IMU) sensor record the prototype master probe displacements.

The Melody robot (Figure 7) was enhanced by replacing the electric motor which performs the $z$ longitudinal real probe motion by a linear actuator, in order to ensure the reversibility of this motion. Furthermore, we added a force sensor which measures the reactive force of the patient's body on the ultrasound probe. On the sonographer's expert side, we first designed an electrically actuated probe replica with different types of motors; neither a DC-motor [105], nor a custom made brushless motor [106], nor a linear motor [107] were able to meet the requirements. Without any reduction, electric driven motors cannot deliver the required force-feedback within a such small hand held volume. Hence, we suggested the use of a pneumatic cylinder as internal VSA for the master probe to be held by the expert, used with a bilateral control scheme, introduced in [108]. This new master probe is used to remotely control the robot which holds and moves the real ultrasound probe in response to the master probe movements. Figure 8 displays the pneumatic haptic probe we designed. The whole probe weighs $240 \mathrm{~g}$. Design details, first basic control approaches and experiment results are provided in [109]. They demonstrate the feasibility of a pneumatic actuation to provide haptic feedback for this kind of ultrasound application, and highlight the need for a more evolved control law such as the one exposed in Section 2.4. Future experimentation, featuring the whole teleoperation loop, will be held to evaluate the overall quality of the whole tele-operated system. In addition, these results will be accompanied by a psychometric study determining whether users are able to recognize common medical cases.
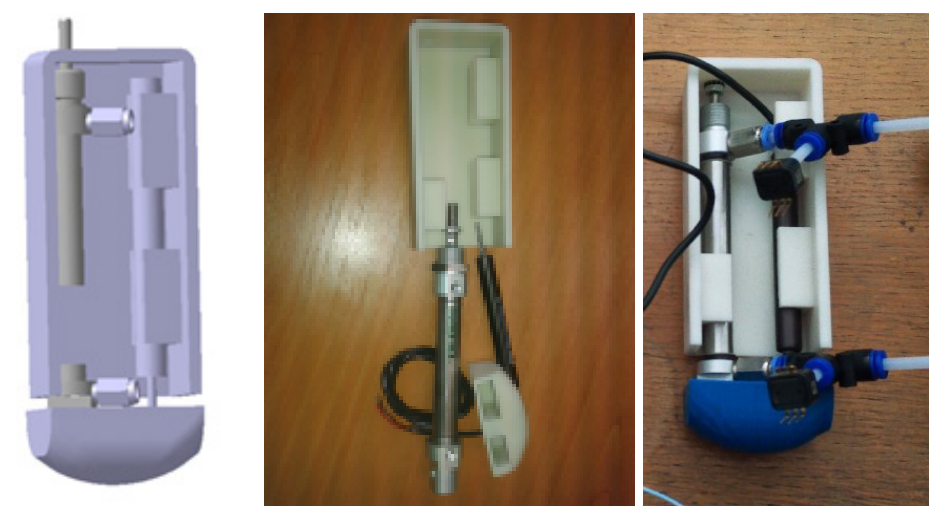

Figure 8. Haptic pneumatic probe (from the left to the right: CAD model, kit and assembled versions).

\section{Conclusions}

In this paper, we reviewed and illustrated the use of pneumatic actuators for medical applications. We recalled the properties of such actuators versus classical electric ones, and highlighted their interest for rendering haptic feedback, when controlled with advanced nonlinear control laws such as the one depicted in Section 2, in order to make them act as Variable Stiffness Actuators. The increasing use of pneumatic actuation but also a hybrid use with electrical motors to combine the advantages of both energies can be noticed. We then presented several applications that we have been working on, based on this approach: the childbirth simulator (BirthSim), the epidural needle insertion simulator (PeriSim) and the haptic master probe for remote ultrasonography. The latter simulator is pneumatic based only, while the two others are hybrid: electric and pneumatic (BirthSim and PeriSim). They all highlight 
the interest of such an approach, especially when the size and form constraints limit the feasibility of electric solutions.

Aside from Birthsim, these applications are in progress. The more advanced one is PeriSim as we are getting enough data to suggest an effective and objective assessment method. the ultrasonography master probe requires further developments (such as the use of aforementioned nonlinear control law) and experiments in a teleoperation context to validate its effectiveness. We are also working on an intra-articular injection (it is one of the most used methods by rheumatologists to treat shoulder pain) under an ultrasonography simulator, which will also use hybrid actuation. First, results about the electric part are available in [110].

Author Contributions: Conceptualisation, T.S., A.L., R.M., C.N., L.N., M.T.P. and P.V.; methodology, T.S., A.L., R.M., C.N. and M.T.P.; software, T.S., A.L. and C.N.; validation, T.S., A.L. and C.N.; supervision, M.T.P. and P.V.; investigation, T.S. and L.N.

Funding: This research was funded by ANR (French National Research Agency, ANR-12-MONU-0006 and ANR-11-IDFI-0034) CNRS (PEPS SoHappy).

Acknowledgments: We thank the Neuroimmersion Tech Facility of the CRNL (Centre de Recherche en Neurosciences de Lyon) for their material support.

Conflicts of Interest: The authors declare no conflict of interest.

Abbreviations
$\begin{array}{ll}\text { The following abbreviations are used in this manuscript: } \\ \text { DOF } & \text { Degrees Of Freedom } \\ \text { FL } & \text { Fuzzy Logic } \\ \text { GPC } & \text { Generalized Predictive Controller } \\ \text { IMU } & \text { Inertial Measurement Unit } \\ \text { LMI } & \text { Linear Matrix Inequality } \\ \text { LOR } & \text { Loss Of Resistance } \\ \text { LVDT } & \text { Linear Variable Differential Transformer } \\ \text { MIS } & \text { Minimal Invasive Surgery } \\ \text { MPC } & \text { Model Predictive Control } \\ \text { MRI } & \text { Magnetic Resonance Imaging } \\ \text { PAM } & \text { Pneumatic Artificial Muscle } \\ \text { PID } & \text { Proportional Integral Derivative } \\ \text { SISO } & \text { Single-Input-Single-Output } \\ \text { VIA } & \text { Variable Impedance Actuator } \\ \text { VSA } & \text { Variable Stiffness Actuator } \\ \text { UAV } & \text { Unmanned Aerial Vehicle }\end{array}$

\section{References}

1. Reznick, R.K.; MacRae, H. Teaching Surgical Skills-Changes in the Wind. N. Engl. J. Med. 2006, 355, 2664-2669. [CrossRef] [PubMed]

2. Spruit, E.N.; Band, G.P.; Hamming, J.F.; Ridderinkhof, K.R. Optimal training design for procedural motor skills: A review and application to laparoscopic surgery. Psychol. Res. 2014, 78, 878-891. [CrossRef] [PubMed]

3. Danzer, E.; Dumon, K.; Kolb, G.; Pray, L.; Selvan, B.; Resnick, A.S.; Morris, J.B.; Williams, N.N. What is the cost associated with the implementation and maintenance of an ACS/APDS-based surgical skills curriculum? J. Surg. Educ. 2011, 68, 519-525. [CrossRef] [PubMed]

4. Granry, J.C.; Moll, M.C. état de l'art (national et international) en matière de pratiques de simulation dans le domaine de la santé; Technical Report; Haute Autorité de la Santé (HAS): Saint-Denis La Plaine, France, 2012.

5. Sutherland, C.; Hashtrudi-Zaad, K.; Sellens, R.; Abolmaesumi, P.; Mousavi, P. An Augmented Reality Haptic Training Simulator for Spinal Needle Procedures. IEEE Trans. Biomed. Eng. 2013, 60, 3009-3018. [CrossRef] [PubMed] 
6. Panait, L.; Akkary, E.; Bell, R.L.; Roberts, K.E.; Dudrick, S.J.; Duffy, A.J. The Role of Haptic Feedback in Laparoscopic Simulation Training. J. Surg. Res. 2009, 156, 312-316. [CrossRef] [PubMed]

7. Carneiro, J.; de Almeida, F. Using two servovalves to improve pneumatic force control in industrial cylinders. Int. J. Adv. Manuf. Technol. 2013, 66, 283-301. [CrossRef]

8. Dawson, D.L.; Meyer, J.; Lee, E.S.; Pevec, W.C. Training with simulation improves residents' endovascular procedure skills. J. Vasc. Surg. 2007, 45, 149-154. [CrossRef]

9. Overtoom, E.M.; Horeman, T.; Jansen, F.W.; Dankelman, J.; Schreuder, H.W.R. Haptic Feedback, Force Feedback, and Force-Sensing in Simulation Training for Laparoscopy: A Systematic Overview. J. Surg. Educ. 2019, 76, 242-261. [CrossRef] [PubMed]

10. Cestari, M.; Sanz-Merodio, D.; Arevalo, J.; Garcia, E. ARES, a variable stiffness actuator with embedded force sensor for the ATLAS exoskeleton. Ind. Robot. Int. J. 2014, 41, 518-526. [CrossRef]

11. Groothuis, S.; Rusticelli, G.; Zucchelli, A.; Stramigioli, S.; Carloni, R. The Variable Stiffness Actuator vsaUT-II: Mechanical Design, Modeling, and Identification. IEEE/ASME Trans. Mechatron. 2014, 19, 589-597. [CrossRef]

12. Jafari, A.; Tsagarakis, N.; Sardellitti, I.; Caldwell, D. A New Actuator With Adjustable Stiffness Based on a Variable Ratio Lever Mechanism. IEEE/ASME Trans. Mechatron. 2014, 19, 55-63. [CrossRef]

13. Takaiwa, M.; Noritsugu, T. Development of pneumatic human interface and its application for compliance display. In Proceedings of the 26th Annual Conference of the IEEE Industrial Electronics Society (IECON 2000), Nagoya, Japan, 22-28 October 2000; Volume 2, pp. 806-811.

14. Semini, C.; Tsagarakis, N.; Guglielmino, E.; Focchi, M.; Cannella, F.; Caldwell, D. Design of HyQ-A hydraulically and electrically actuated quadruped robot. Syst. Control Eng. 2011, 225, 831-849. [CrossRef]

15. Kamiya, N.; Kiyoshi, O.; Yokokura, Y.; Miyazaki, T. Force sensorless force control using notch-type friction free disturbance observer. In Proceedings of the 2018 IEEE 15th International Workshop on Advanced Motion Control (AMC), Tokyo, Japan, 9-11 March 2018; pp. 643-648. [CrossRef]

16. Schindlbeck, C.; Haddadin, S. Unified passivity-based Cartesian force/impedance control for rigid and flexible joint robots via task-energy tanks. In Proceedings of the 2015 IEEE International Conference on Robotics and Automation (ICRA), Seattle, WA, USA, 26-30 May 2015; pp. 440-447. [CrossRef]

17. Mendes, N.; Neto, P.; Loureiro, A.; Moreira, A.P. Machines and control systems for friction stir welding: A review. Mater. Des. 2016, 90, 256-265. [CrossRef]

18. Calanca, A.; Muradore, R.; Fiorini, P. A Review of Algorithms for Compliant Control of Stiff and Fixed-Compliance Robots. IEEE/ASME Trans. Mechatron. 2016, 21, 613-624. [CrossRef]

19. Hughes, J.; Culha, U.; Giardina, F.; Guenther, F.; Rosendo, A.; Iida, F. Soft Manipulators and Grippers: A Review. Front. Robot. AI 2016, 3, 69. [CrossRef]

20. Lasota, P.A.; Fong, T.; Shah, J.A. A Survey of Methods for Safe Human-Robot Interaction. Found. Trends ${ }^{\circledR}$ Robot. 2017, 5, 261-349. [CrossRef]

21. Corrêa, C.G.; Nunes, F.L.; Ranzini, E.; Nakamura, R.; Tori, R. Haptic interaction for needle insertion training in medical applications: The state-of-the-art. Med. Eng. Phys. 2019, 63, 6-25. [CrossRef] [PubMed]

22. Krupa, A.; Folio, D.; Novales, C.; Vieyres, P.; Li, T. Robotized Tele-Echography: An Assisting Visibility Tool to Support Expert Diagnostic. IEEE Syst. J. 2016, 10, 974-983. [CrossRef]

23. Son, H.I. The contribution of force feedback to human performance in the teleoperation of multiple unmanned aerial vehicles. J. Multimodal User Interfaces 2019. [CrossRef]

24. Kheddar, A.; Devine, C.; Brunel, M.; Duriez, C.; Sibony, O. Preliminary design of a childbirth simulator haptic feedback. In Proceedings of the IEEE Intelligent Robots and Systems Conference, Sendai, Japan, 28 September-2 October 2004; Volume 4, pp. 3270-3275.

25. Van Ham, R.; Sugar, T.; Vanderborght, B.; Hollander, K.; Lefeber, D. Compliant actuator designs. IEEE Robot. Autom. Mag. 2009, 16, 81-94. [CrossRef]

26. Huang, Y.; Vanderborght, B.; Van Ham, R.; Wang, Q.; Van Damme, M.; Xie, G.; Lefeber, D. Step Length and Velocity Control of a Dynamic Bipedal Walking Robot With Adaptable Compliant Joints. IEEE/ASME Trans. Mechatron. 2013, 18, 598-611. [CrossRef]

27. Salisbury, J. Active stiffness control of a manipulator in cartesian coordinates. In Proceedings of the 198019 th IEEE Conference onDecision and Control including the Symposium on Adaptive Processes, Albuquerque, NM, USA, 10-12 December 1980; pp. 95-100. [CrossRef] 
28. Hogan, N. Stable execution of contact tasks using impedance control. In Proceedings of the 1987 IEEE International Conference on Robotics and Automation, Raleigh, NC, USA, 31 March-3 April 1987; Volume 4, pp. 1047-1054. [CrossRef]

29. Hayati, S. Hybrid position/Force control of multi-arm cooperating robots. In Proceedings of the 1986 IEEE International Conference on Robotics and Automation, San Francisco, CA, USA, 7-10 April 1986; Voume 3, pp. 82-89. [CrossRef]

30. Saravanakumar, D.; Mohan, B.; Muthuramalingam, T. A review on recent research trends in servo pneumatic positioning systems. Precis. Eng. 2017, 49, 481-492. [CrossRef]

31. Ben-Dov, D.; Salcudean, S. A force-controlled pneumatic actuator for use in teleoperation masters. In Proceedings of the IEEE International Conference on Robotics and Automation (ICRA'93), Atlanta, GA, USA, 2-6 May 1993; pp. 938-943.

32. Le, M.; Pham, M.; Tavakoli, M.; Moreau, R.; Simon, J.; Redarce, T. Bilateral Control of a Nonlinear Pneumatic Teleoperation System with Solenoid Valves. Trans. Control Syst. Technol. (TCST) 2013, 21, 1463-1470. [CrossRef]

33. Rognon, C.; Wu, A.R.; Mintchev, S.; Ijspeert, A.; Floreano, D. Haptic Guidance with a Soft Exoskeleton Reduces Error in Drone Teleoperation. In Haptics: Science, Technology, and Applications; Prattichizzo, D., Shinoda, H., Tan, H.Z., Ruffaldi, E., Frisoli, A., Eds.; Springer International Publishing: Cham, Switzerland, 2018; pp. 404-415. [CrossRef]

34. Turkseven, M.; Ueda, J. Model-Based Force Control of Pneumatic Actuators with Long Transmission Lines. IEEE/ASME Trans. Mechatron. 2018, 23, 1292-1302. [CrossRef]

35. Yap, H.K.; Lim, J.H.; Nasrallah, F.; Goh, J.C.H.; Yeow, R.C.H. A soft exoskeleton for hand assistive and rehabilitation application using pneumatic actuators with variable stiffness. In Proceedings of the 2015 IEEE International Conference on Robotics and Automation (ICRA), Seattle, WA, USA, 25-30 May 2015; pp. 4967-4972. [CrossRef]

36. Best, C.M.; Gillespie, M.T.; Hyatt, P.; Rupert, L.; Sherrod, V.; Killpack, M.D. A New Soft Robot Control Method: Using Model Predictive Control for a Pneumatically Actuated Humanoid. IEEE Robot. Autom. Mag. 2016, 23, 75-84. [CrossRef]

37. Fischer, G.S.; Iordachita, I.; Csoma, C.; Tokuda, J.; DiMaio, S.P.; Tempany, C.M.; Hata, N.; Fichtinger, G. MRI-Compatible Pneumatic Robot for Transperineal Prostate Needle Placement. IEEE/ASME Trans. Mechatron. 2008, 13, 295-305. [CrossRef] [PubMed]

38. Ugurlu, B.; Forni, P.; Doppmann, C.; Morimoto, J. Torque and variable stiffness control for antagonistically driven pneumatic muscle actuators via a stable force feedback controller. In Proceedings of the 2015 IEEE/RSJ International Conference on Intelligent Robots and Systems (IROS), Hamburg, Germany, 28 September-2 October 2015; pp. 1633-1639. [CrossRef]

39. Tiziani, L.O.; Cahoon, T.W.; Hammond, F.L. Sensorized pneumatic muscle for force and stiffness control. In Proceedings of the 2017 IEEE International Conference on Robotics and Automation (ICRA), Singapore, 29 May-3 June 2017; pp. 5545-5552. [CrossRef]

40. Okui, M.; Kobayashi, M.; Yamada, Y.; Nakamura, T. Delta-type four-DOF force-feedback device composed of pneumatic artificial muscles and magnetorheological clutch and its application to lid opening. Smart Mater. Struct. 2019, 28, 064003. [CrossRef]

41. Andersen, B. The Analysis and Design of Pneumatic Systems; Wiley: Hoboken, NJ, USA, 1967.

42. Hodgson, S.; Tavakoli, M.; Lelevé, A.; Pham, M.T. High-fidelity sliding mode control of a pneumatic haptic teleoperation system. Adv. Robot. 2014, 28, 659-671. [CrossRef]

43. Bobrow, J.; McDonell, B. Modeling, identification, and control of a pneumatically actuated, force controllable robot. IEEE Trans. Robot. Autom. 1998, 14, 732-742. [CrossRef]

44. Herzig, N.; Moreau, R.; Redarce, T.; Abry, F.; Brun, X. Nonlinear position and stiffness Backstepping controller for a two Degrees of Freedom pneumatic robot. Control Eng. Pract. 2018, 73, 26-39. [CrossRef]

45. Utkin, V.; Guldner, J.; Shi, J. Sliding Mode Control in Electro-Mechanical Systems; Taylor and Francis: Abingdon, UK, 2009. [CrossRef]

46. Khalil, H.K. Nonlinear Systems I; Prentice Hal: Upper Saddle River, NJ, USA, 2002. [CrossRef]

47. Toedtheide, A.; Lilge, T.; Haddadin, S. Antagonistic Impedance Control for Pneumatically Actuated Robot Joints. IEEE Robot. Autom. Lett. 2016, 1, 161-168. [CrossRef] 
48. Talhan, A.; Jeon, S. Pneumatic Actuation in Haptic-Enabled Medical Simulators: A Review. IEEE Access 2018, 6, 3184-3200. [CrossRef]

49. Hwang, J.; Gu, Y.; Lee, D.Y. A pneumatic haptic module for simulation of catheters used in gastrointestinal endoscopy. In Proceedings of the 2016 16th International Conference on Control, Automation and Systems (ICCAS), Gyeongju, Korea, 16-19 October 2016; pp. 287-291. [CrossRef]

50. Franco, E.; Rea, M.; Gedroyc, W.; Ristic, M. Control of a Master-Slave Pneumatic System for Teleoperated Needle Insertion in MRI. IEEE/ASME Trans. Mechatron. 2016, 21, 2595-2600. [CrossRef]

51. Miyazaki, R.; Kanno, T.; Endo, G.; Kawashima, K. Pneumatically driven handheld forceps with force display operated by motion sensor. In Proceedings of the 2015 IEEE International Conference on Robotics and Automation (ICRA), Seattle, WA, USA, 26-30 May 2015; pp. 604-609. [CrossRef]

52. Morimoto, T.; Akagi, T.; Dohta, S.; Matsui, Y. Development of Flexible Displacement Sensor Using Ultrasonic Sensor for Flexible Pneumatic Robot Arm. Procedia Comput. Sci. 2015, 76, 107-112. [CrossRef]

53. Fras, J.; Althoefer, K. Soft Pneumatic Prosthetic Hand. In Towards Autonomous Robotic Systems; Giuliani, M., Assaf, T., Giannaccini, M.E., Eds.; Springer International Publishing: Cham, Switzerland, 2018; pp. 112-120.

54. Gopura, R.; Bandara, D.; Kiguchi, K.; Mann, G. Developments in hardware systems of active upper-limb exoskeleton robots: A review. Robot. Auton. Syst. 2016, 75, 203-220. [CrossRef]

55. Shen, Y.; Ferguson, P.W.; Ma, J.; Rosen, J. Chapter 4-Upper Limb Wearable Exoskeleton Systems for Rehabilitation: State of the Art Review and a Case Study of the EXO-UL8-Dual-Arm Exoskeleton System. In Wearable Technology in Medicine and Health Care; Tong, R.K.Y., Ed.; Academic Press: Cambridge, MA, USA, 2018; pp. 71-90. [CrossRef]

56. Barsotti, M.; Stroppa, F.; Mastronicola, N.; Marcheschi, S.; Frisoli, A. Teleoperated Bilateral-Arm Rehabilitation with ALEx Rehab Station. In Converging Clinical and Engineering Research on Neurorehabilitation III; Masia, L., Micera, S., Akay, M., Pons, J.L., Eds.; Springer International Publishing: Cham, Switzerland, 2019; pp. 185-189. [CrossRef]

57. Veale, A.J.; Xie, S.Q. Towards compliant and wearable robotic orthoses: A review of current and emerging actuator technologies. Med. Eng. Phys. 2016, 38, 317-325. [CrossRef] [PubMed]

58. Polygerinos, P.; Correll, N.; Morin, S.A.; Mosadegh, B.; Onal, C.D.; Petersen, K.; Cianchetti, M.; Tolley, M.T.; Shepherd, R.F. Soft Robotics: Review of Fluid-Driven Intrinsically Soft Devices; Manufacturing, Sensing, Control, and Applications in Human-Robot Interaction. Adv. Eng. Mater. 2017, 19, 1700016. [CrossRef]

59. Cianchetti, M.; Laschi, C.; Menciassi, A.; Dario, P. Biomedical applications of soft robotics. Nat. Rev. Mater. 2018, 3, 143-153. [CrossRef]

60. Chen, G.; Pham, M.T.; Redarce, T. Sensor-based guidance control of a continuum robot for a semi-autonomous colonoscopy. Robot. Auton. Syst. 2009, 57, 712-722. [CrossRef]

61. Stanley, A.A.; Okamura, A.M. Controllable Surface Haptics via Particle Jamming and Pneumatics. IEEE Trans. Haptics 2015, 8, 20-30. [CrossRef]

62. Fukuda, T.; Tanaka, Y.; Kappers, A.M.L.; Fujiwara, M.; Sano, A. A Pneumatic Tactile Ring for Instantaneous Sensory Feedback in Laparoscopic Tumor Localization. IEEE Trans. Haptics 2018, 11, 485-497. [CrossRef] [PubMed]

63. Talhan, A.; Kim, H.; Kumar, S.; Raza, A.; Jeon, S. Pneumatic Actuated Haptic Glove to Interact with the Virtual Human. In Haptic Interaction; Kajimoto, H., Lee, D., Kim, S.Y., Konyo, M., Kyung, K.U., Eds.; Springer: Singapore, 2019; pp. 213-215.

64. Gaudeni, C.; Meli, L.; Prattichizzo, D. A Novel Pneumatic Force Sensor for Robot-Assisted Surgery. In Haptics: Science, Technology, and Applications; Prattichizzo, D., Shinoda, H., Tan, H.Z., Ruffaldi, E., Frisoli, A., Eds.; Springer International Publishing: Cham, Switzerland, 2018; pp. 587-599.

65. Shang, W.; Su, H.; Li, G.; Fischer, G.S. Teleoperation system with hybrid pneumatic-piezoelectric actuation for MRI-guided needle insertion with haptic feedback. In Proceedings of the 2013 IEEE/RSJ International Conference on Intelligent Robots and Systems, Tokyo, Japan, 3-7 November 2013; pp. 4092-4098. [CrossRef]

66. Cinq-Mars, M.; Gurocak, H. Pneumatic cylinder with magnetorheological brake using serpentine and helix flux guide as a linear hybrid actuator for haptics. J. Intell. Mater. Syst. Struct. 2017, 28, 1303-1321. [CrossRef]

67. Takikawa, K.; Miyazaki, R.; Kanno, T.; Endo, G.; Kawashima, K. Pneumatically Driven Multi-DOF Surgical Forceps Manipulator with a Bending Joint Mechanism Using Elastic Bodies. J. Robot. Mechatron. 2016, 28, 559-567. [CrossRef] 
68. Rahman, R.A.; He, L.; Sepehri, N. Design and experimental study of a dynamical adaptive backstepping-sliding mode control scheme for position tracking and regulating of a low-cost pneumatic cylinder. Int. J. Robust Nonlinear Control 2016, 26, 853-875. [CrossRef]

69. Shearer, J. Study of pneumatic processes in the continuous control of motion with compressed air: Part I and II. Trans. ASME 1956, 78, 233-249.

70. Wikander, J. Adaptive Control of Pneumatic Cylinders. Ph.D. Thesis, Royal Institute of Technology, Department of Machine Elements, Stockholm, Sweden, 1988.

71. Chikh, L.; Poignet, P.; Pierrot, F.; Michelin, M. A Generalized Predictive Force Controller for electropneumatic cylinders. In Proceedings of the 8th IFAC Symposium on Nonlinear Control Systems (NOLCOS'2010), Bologna, Italy, 1-3 September 2010.

72. Chikh, L.; Poignet, P.; Pierrot, F.; Baradat, C. A mixed GPC-H infinity robust cascade position-pressure control strategy for electropneumatic cylinders. In Proceedings of the IEEE International Conference on Robotics and Automation (ICRA'10), Anchorage, AK, USA, 3-7 May 2010.

73. Ren, H.; Wang, X.; Fan, J.; Kaynak, O. Adaptive Backstepping Control of a Pneumatic System With Unknown Model Parameters and Control Direction. IEEE Access 2019, 7, 64471-64482. [CrossRef]

74. Garmsiri, N.; Sun, Y.; Yang, C.; Sepehri, N. Bilateral teleoperation of a pneumatic actuator: Experiment and stability analysis. Int. J. Fluid Power 2015, 16, 99-110. [CrossRef]

75. Hajji, S.; Ayadi, A.; Smaoui, M.; Maatoug, T.; Farza, M.; M'saad, M. Position Control of Pneumatic System Using High Gain and Backstepping Controllers. J. Dyn. Syst. Meas. Control 2019, 141, 081001. [CrossRef]

76. Abry, F.; Brun, X.; Sesmat, S.; Bideaux, E. Nonlinear position control of a pneumatic actuator with closed-loop stiffness and damping tuning. In Proceedings of the European Control Conference 2013, Zurich, Switzerland, 17-19 July 2013.

77. Abry, F.; Brun, X.; Sesmat, S.; Bideaux, E.; Ducat, C. Electropneumatic Cylinder Backstepping Position Controller Design With Real-Time Closed-Loop Stiffness and Damping Tuning. IEEE Trans. Control Syst. Technol. 2016, 24, 541-552. [CrossRef]

78. Liu, H.; Hirzinger, G. Joint torque based Cartesian impedance control for the DLR hand. In Proceedings of the IEEE/ASME Intl. Conf. on Advanced Intelligent Mechatronics, Atlanta, GA, USA, 19-23 September 1999; pp. 695-700. [CrossRef]

79. Sénac, T.; Lelevé, A.; Moreau, R.; Krahenbuhl, L.; Sigwalt, F.; Bauer, C.; Rouby, Q. Designing an accurate and customizable epidural anesthesia haptic simulator. In Proceedings of the IEEE International Conference on Robotics and Automation (ICRA), Montreal, QC, Canada, 20-24 May 2019.

80. Lapeer, R.; Chen, M.; Villagrana, J. Simulating Obstetric Forceps Delivery in an Augmented Environment. In Proceedings of the AMI/ARCS sattelite workshop of MICCAI 2004, Copenhagen, Denmark, 30 September 2004; pp. 1-10.

81. Sielhorst, T.; Blum, T.; Navab, N. Synchronizing 3D Movements for Quantitative Comparison and Simultaneous Visualization of Actions. In Proceedings of the 4th IEEE/ ACM International Symposium on Mixed and Augmented Reality (ISMAR'05), Washington, DC, USA, 5 December 2005; pp. 38-47. [CrossRef]

82. Abate, A.F.; Acampora, G.; Loia, V.; Ricciardi, S.; Vasilakos, A.V. A Pervasive Visual-Haptic Framework for Virtual Delivery Training. IEEE Trans. Inf. Technol. Biomed. 2010, 14, 326-334. [CrossRef]

83. Deering, S.; Brown, J.; Hodor, J.; Satin, A.J. Simulation training and resident performance of singleton vaginal breech delivery. Obstet. Gynecol. 2006, 107, 86-89. [CrossRef] [PubMed]

84. Silveira, R.; Pham, M.T.; Redarce, T.; Betemps, M.; Dupuis, O. A new mechanical birth simulator: BirthSIM. In Proceedings of the 2004 IEEE/RSJ International Conference on Intelligent Robots and Systems (IROS) (IEEE Cat. No.04CH37566), Sendai, Japan, 28 September-2 October 2004.

85. Moreau, R.; Pham, M.T.; Silveira, R.; Redarce, T.; Brun, X.; Dupuis, O. Design of a New Instrumented Forceps: Application to Safe Obstetrical Forceps Blade Placement. IEEE Trans. Biomed. Eng. 2007, 54, 1280-1290. [CrossRef] [PubMed]

86. Konrad, C.; Schupfer, G.; Wietlisbach, M.; Gerber, H. Learning Manual Skills in Anesthesiology: Is There a Recommended Number of Cases for Anesthetic Procedures? Anesth. Analg. 1998, 86, 635. [CrossRef] [PubMed]

87. Vaughan, N.; Dubey, N.; Venketesh, M.Y.; Wee, K.; Isaacs, R. A review of epidural simulators: Where are we today? Med. Eng. Phys. 2013, 35, 1235-1250. [CrossRef] 
88. Manoharan, V.; van Gerwen, D.; van den Dobbelsteen, J.J.; Dankelman, J. Design and validation of an epidural needle insertion simulator with haptic feedback for training resident anaesthesiologists. In Proceedings of the 2012 IEEE Haptics Symposium (HAPTICS), Vancouver, BC, Canada, 4-7 March 2012; pp. 341-348.

89. Magill, J.C.; Byl, M.F.; Hinds, M.F.; Agassounon, W.; Pratt, S.D.; Hess, P.E. A Novel Actuator for Simulation of Epidural Anesthesia and Other Needle Insertion Procedures. Simul. Heal. J. Soc. Simul. Healthc. 2010, 5, 179-184. [CrossRef] [PubMed]

90. Dubey, V.; Vaughan, N.; Wee, M.Y.K.; Isaacs, R. Biomedical Engineering in Epidural Anaesthesia Research. In Practical Applications in Biomedical Engineering; Andrade, A., Ed.; InTech: London, UK, 2013. [CrossRef]

91. Dang, T.; Annaswamy, T.M.; Srinivasan, M.A. Development and Evaluation of an Epidural Injection Simulator with Force Feedback for Medical Training. Stud. Health Technol. Inform. 2001, 81, 97-102. [CrossRef] [PubMed]

92. Senac, T.; Lelevé, A.; Moreau, R. Control laws for pneumatic cylinder in order to emulate the Loss of Resistance principle. In Proceedings of the IFAC 2017-20th World Congress of the International Federation of Automatic Control, Toulouse, France, 9-14 July 2017; IIFAC: Toulouse, France, 2017.

93. Gourdon, A.; Poignet, P.; Poisson, G.; Vieyres, P.; Marche, P. A new robotic mechanism for medical application. In Proceedings of the IEEE/ASME International Conference on Advanced Intelligent Mechatronics (AIM 1999), Atlanta, GA, USA, 19-23 September 1999; pp. 33-38. [CrossRef]

94. Courreges, F.; Smith-Guerin, N.; Poisson, G.; P.Vieyres.; Gourdon, A.; Szpieg, M.; Merigeaux, O. Real-time exhibition of a simulated space tele-echography using an ultra-light robot. In Proceedings of the ISAIRAS Conference, Montreal, QC, Canada, 18-22 June 2001.

95. Vilchis Gonzales, A.; Cinquin, P.; Troccaz, J.; Guerraz, A.; Hennion, B.; Pellissier, F.; Thorel, P.; Courreges, F.; Gourdon, A.; Poisson, G.; et al. TER: A System for Robotic Tele-echography. In Medical Image Computing and Computer-Assisted Intervention (MICCAI 2001); Niessen, W., Viergever, M., Eds.; Springer: Berlin/Heidelberg, Germany, 2001; Lecture Notes in Computer Science; Volume 2208, pp. 326-334. [CrossRef]

96. Masuda, K.; Kimura, E.; Tateishi, N.; Ishihara, K. Three dimensional motion mechanism of ultrasound probe and its application for tele-echography system. In Proceedings of the IEEE/RSJ International Conference on Intelligent Robots and Systems, Maui, HI, USA, 29 October-3 November 2001; Volume 2, pp. 1112-1116. [CrossRef]

97. Najafi, F.; Sepehri, N. A novel hand-controller for remote ultrasound imaging. Mechatronics 2008, 18, 578-590. [CrossRef]

98. Nouaille, L.; Vieyres, P.; Poisson, G. Process of optimisation for a 4 DOF tele-echography robot. Robotica 2012, 30, 1131-1145. [CrossRef]

99. Ito, K.; Sugano, S.; Iwata, H. Portable and Attachable TeleEchography Robot System: FASTele. In Proceedings of the Annual International Conference of the IEEE Engineering in Medicine and Biology Society (EMBC), Buenos Aires, Argentina, 31 August-4 September 2010; pp. 487-490.

100. Mathiassen, K.; Fjellin, J.E.; Glette, K.; Hol, P.K.; Elle, O.J. An Ultrasound Robotic System Using the Commercial Robot UR5. Front. Robot. AI 2016, 3, 1. [CrossRef]

101. Conti, F.; Park, J.; Khatib, O. Interface Design and Control Strategies for a Robot Assisted Ultrasonic Examination System. In Proceedings of the 12th International Symposium on Experimental Robotics, Marrakech and Essaouira, Morocco, 15-18 June 2014; Khatib, O., Kumar, V., Sukhatme, G., Eds.; Springer: Berlin/Heidelberg, Germany, 2014; pp. 97-113. [CrossRef]

102. Arent, K.; Cholewiński, M.; Chojnacki, L.; Domski, W.; Drwięga, M.; Jakubiak, J.; Janiak, M.; Kreczmer, B.; Kurnicki, A.; Stańczyk, B.; et al. Selected topics in design and application of a robot for remote medical examination with the use of ultrasonography and ascultation from the perspective of the REMEDI project. J. Autom. Mob. Robot. Intell. Syst. 2017, 11, 82-94. [CrossRef]

103. Courreges, F.; Novales, C.; Poisson, G.; Vieyres, P. Modelisation, commande geometrique et utilisation d'un robot portable de tele-echographie: Teresa. J. Eur. Des Syst. Autom. (JESA) 2009, 43, 165-196. ISSN 12696935. [CrossRef] 
104. Vieyres, P.; Novales, C.; Rivas, R.; Vilcahuaman, L.; Sandoval, J.; Clark, T.; DeStigter, K.; Josserand, L.; Morrison, Z.; Robertson, A.; et al. The next challenge for WOrld wide Robotized Tele-Echography eXperiment (WORTEX 2012): From engineering success to healthcare delivery. In Proceedings of the TUMI II, Congreso Peruano de Ingeniera Biomedical Bioingeniera, Biotecnologica y Fisica Medica, Lima, Peru, 29-31 May 2013.

105. Mourioux, G.; Novales, C.; Smith-Guerin, N.; Vieyres, P.; Poisson, G. A free haptic device for tele-echography. In Proceedings of the International Workshop on Research and Education in Mechatronics (REM'2005), Annecy, France, 30 June-1 July 2005.

106. Charron, G.; Morette, N.; Essomba, T.; Vieyres, P.; Canou, J.; Fraisse, P.; Zeghloul, S.; Krupa, A.; Arbeille, P. Robotic Platform for an Interactive Tele-echographic System: The PROSIT ANR-2008 project. In Proceedings of the Hamlyn Symposium on Medical Robotics, London, UK, 25 May 2010.

107. Vieyres, P.; Sandoval, J.; Josserand, L.; Novales, C.; Chiccoli, M.; Morette, N.; Fonte, A.; Avgousti, S.; Voskarides, S.; Kasparis, T. An Anticipative Control Approach and Interactive GUI to Enhance the Rendering of the Distal Robot Interaction with Its Environment During Robotized Tele-Echography: Interactive Platform for Robotized Tele-Echography. Int. J. Monit. Surveill. Technol. Res. 2013, 1, 1-19. [CrossRef]

108. Vieyres, P.; Poisson, G.; Courreges, F.; Smith-Guerin, N.; Novales, C.; Arbeille, P. A Tele-Operated Robotic System for Mobile Tele-Echography: The Otelo Project. In M-Health; Istepanian Robert, S., Laxminarayan, S., Pattichis, C.S., Eds.; Topics in Biomedical Engineering; Springer US: New York, NY, USA, 2006; pp. 461-473. [CrossRef]

109. Abdallah, I.; Gatwaza, F.; Morette, N.; Lelevé, A.; Novales, C.; Nouaille, L.; Brun, X.; Vieyres, P. A Pneumatic Haptic Probe Replica for Tele-Robotized Ultrasonography. In Proceedings of the International Conference on Smart Multimedia (ICSM-2018), Toulon, France, 24-26 August 2018; Lecture Notes in Computer Science, Chapter Smart Multimedia (ICSM 2018); Basu A., Berretti, S., Eds.; Springer: Toulon, France, 2018; Volume 11010.

110. Alamilla D., M.d.1.A.; Moreau, R.; Redarce, T. A new method to render virtual walls for haptic systems: "Tracking wall". In Proceedings of the 2018 7th International Conference on Mechatronics and Control Engineering (ICMCE 2018), Amsterdam, The Netherlands, 27-29 November 2018.

(C) 2019 by the authors. Licensee MDPI, Basel, Switzerland. This article is an open access article distributed under the terms and conditions of the Creative Commons Attribution (CC BY) license (http:/ / creativecommons.org/licenses/by/4.0/). 